\title{
HUBUNGAN PENGETAHUAN TERHADAP PERILAKU PENGGUNAAN GREEN PACKAGING DI MASYARAKAT KOTA BANDUNG, JAWA BARAT
}

\section{THE RELATIONSHIP BETWEEN KNOWLEDGE AND BEHAVIOR TO USE OF GREEN PACKAGING IN BANDUNG CITY, WEST JAVA}

\author{
Nahda Amalia*, Yosini Deliana \\ Program Studi Agribisnis, Fakultas Pertanian, Universitas Padjadjaran \\ Jl. Raya Jatinangor Sumedang Km. 21 \\ *E-mail : amalia.nahda@gmail.com \\ (Diterima 16-08-2020; Disetujui 01-11-2020)
}

\begin{abstract}
ABSTRAK
Permasalahan lingkungan dapat terjadi karena aktivitas manusia. Kota Bandung merupakan salah satu wilayah yang padat penduduk dan menjadi daya tarik wisata sehingga dapat menyebabkan permasalahan lingkungan seperti sampah plastik. Volume sampah plastik terbesar di Kota Bandung disumbang dari ritel, pasar tradisional, dan masyarakat yang menggunakan kantong plastik. Penelitian ini bertujuan untuk mengetahui hubungan pengetahuan dan perilaku penggunaan green packaging sebagai salah satu upaya mengurangi sampah plastik pada masyarakat Kota Bandung. Penelitian ini termasuk ke dalam tipe penelitian kuantitatif dengan metode survei dan analisis menggunakan korelasi pearson. Hasil analisis menunjukkan bahwa semakin tinggi tingkat pengetahuan masyarakat tentang green packaging tidak berpengaruh baik terhadap perilaku penggunaan green packaging. Faktor dominan yang menjadi pertimbangan masyarakat dalam mengenal dan menggunakan green packaging adalah media sosial dan lingkungan sosial sekitar. Sebagian masyarakat juga mulai berupaya untuk menggunakan green packaging dengan membawa kantong belanja sendiri, menggunakan botol minum dan tempat makan sendiri saat berkunjung, dan bersedia untuk mengedukasi orang-orang sekitar agar menggunakan green packaging untuk membantu melestarikan lingkungan.
\end{abstract}

Kata kunci : Pengetahuan, Perilaku, Analisis Korelasi Pearson, Green Packaging

\section{ABSTRACT}

Environmental problems can occur due to human activities. Bandung City is a densely populated area and a tourist attraction that can cause environmental problems such as plastic waste. The largest volume of plastic waste in Bandung City is contributed from retail, traditional markets, and the people who use plastic bags. This study aims to determine the relationship between knowledge and behavior of using green packaging as an effort to reduce plastic waste in Bandung City. This research belongs to the type of quantitative research with survey and analysis methods using pearson correlation. The result shows that the higher level of public knowledge about green packaging does not have a good effect on the behavior of using green packaging. The dominant factor that is considered by the public in recognizing and using green packaging is social media and the surrounding social environment. Some people have also begun to try to use green packaging by bringing their own shopping bags, using drinking bottles and lunch boxes themselves when traveling, and are willing to educate people around to use green packaging to help preserve the environment.

Keywords: Knowledge, Behavior, Pearson Correlation Analysis, Green Packaging 


\section{PENDAHULUAN}

Seiring berkembangnya teknologi yang membuat semua serba instan membuat gaya hidup masyarakat menjadi berubah dan memilih sesuatu yang praktis dan mudah. Salah satunya adalah dalam hal memilih produk makanan dan minuman siap saji yang dikemas menggunakan kemasan plastik. Hal tersebut tentu berdampak negatif jika sampah plastik yang tidak di daur ulang dan berakhir di lingkungan berpotensi mencemari dan merusak ekosistem (Rosadi, 2019).

Menurut penelitian Jambeck (2015), Indonesia menduduki peringkat kedua di bawah Tiongkok sebagai negara paling mencemari laut dengan sampah plastik di dunia yang berjumlah kurang lebih 3,2 juta ton sampah plastik per tahunnya. Tentu peringkat tersebut bukanlah suatu prestasi yang harus dibanggakan, melainkan harus segera ditangani. Faktanya diketahui bahwa saat ini plastik merupakan barang yang tidak terlepas pada setiap kegiatan manusia.

Qodriyatun (2018) menyebutkan sampah plastik membutuhkan waktu 500 sampai 1.000 tahun untuk dapat terurai. Efek dari limbah sampah yang tidak terurai akan tertimbun di dalam tanah dan merusak tanah dan air tanah. Selain itu, dapat berdampak buruk terhadap kesehatan apabila digunakan dalam jangka panjang.

Kota Bandung merupakan salah satu daerah tujuan wisata masyarakat di Indonesia. Julukan sebagai kota kembang dan kota sejuta kenangan menjadikan kota Bandung memiliki daya tarik sendiri untuk dikunjungi. Selain suhu dan udaranya yang sejuk, Kota Bandung juga mempunyai berbagai keunikan seperti bangunan bersejarah, makanan khas, dan lain sebagainya. Sukriah mengatakan bahwa Kota Bandung memiliki kelebihan dan daya tarik wisata tinggi yang bisa menjadikan Kota Bandung sebagai tujuan wisatawan. Banyaknya jumlah wisatawan yang datang mengunjungi kota Bandung tidak hanya memberikan dampak positif berupa peningkatan pendapatan daerah, melainkan juga dampak negatif salah satunya adalah bertambahnya jumlah sampah plastik. Sampah plastik dapat dihasilkan karena adanya aktivitas berbelanja, konsumsi, maupun rekreasi.

Terlihat pada Gambar 1 bahwa sampah yang dihasilkan di Kota Bandung tahun 2018 paling banyak adalah sampah makanan dan daun sebanyak 44\% dari total sampah yang dihasilkan. Namun, sampah makanan dan daun mudah terurai 
berbeda halnya dengan sampah plastik yang menduduki peringkat kedua sebagai penyumbang sampah di Kota Bandung yang sulit untuk diurai dan apabila dibiarkan akan menjadi permasalahan jangka panjang.

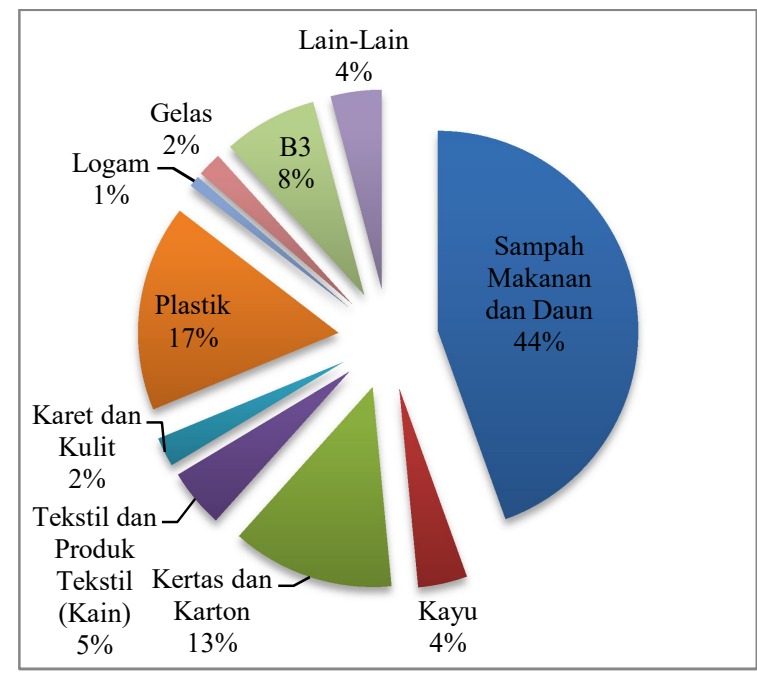

Gambar 1. Komposisi Sampah di Kota

Bandung 2018

(Sumber: PD Kebersihan Kota Bandung, 2019)

Semakin maraknya berita banjir akibat sampah plastik dan bahaya sampah plastik yang disebarluaskan melalui media cetak maupun elektronik tentu mengubah pola pikir masyarakat menjadi lebih peduli terhadap lingkungan dan menghindari penggunaan plastik dalam kehidupan sehari-hari. Konsep green marketing muncul sebagai perhatian terhadap isu-isu kerusakan lingkungan yang kemudian digunakan oleh perusahaan sebagai salah satu strategi dalam pemasarannya (Choudhary dan Samir, 2013).
Green marketing didefinisikan sebagai respon pemasaran terhadap pengaruh lingkungan yang berasal dari perancangan, produksi, pengemasan, pelabelan, penggunaan, dan pembuangan barang atau jasa (Setiyaningrum et al, 2015). Salah satu yang harus diperhatikan dalam menjalankan konsep green marketing adalah menerapkan konsep Green Packaging.

Green Packaging merupakan upaya pengurangan kemasan yang berbahan dasar plastik. Green Packaging membantu berkurangnya kemasan yang sulit terdegradasi (non-biodegradable) dan juga dapat menarik perhatian konsumen karena memiliki dampak positif bagi lingkungan. Menurut Carlson (2009), Green Packaging harus memiliki manfaat bagi konsumen seperti kemasan yang aman dan sehat, kemasan yang ramah lingkungan diproduksi, diangkut, dan didaur ulang melalui sumber energi yang baru, serta memaksimalkan penggunaan bahan yang terbarukan atau dapat didaur ulang menggunakan teknologi produksi bersih dan praktik terbaik, dapat dirancang untuk mengoptimalkan bahan dan energi yang digunakan agar lebih efektif.

Banyaknya aktivitas peduli lingkungan dan demo peduli lingkungan 
seperti penanaman 1.000 pohon, say no to plastic, dan adanya banyak informasi tentang kegunaan Green Packaging semakin menambah pengetahuan masyarakat tentang bahaya plastik. Semakin tingginya tingkat pengetahuan masyarakat terhadap kerusakan lingkungan yang dihasilkan oleh sampah plastik dan kesadaran akan produk ramah lingkungan diharapkan mampu mempengaruhi perilaku masyarakat itu sendiri untuk menjadi pribadi yang lebih peduli pada lingkungan.

Hal tersebut sejalan dengan penelitian yang dilakukan oleh Fauzia et al (2016) yang menyatakan adanya hubungan yang signifikan antara pengetahuan dan perilaku karena pengetahuan merupakan salah satu stimulus dalam pembentukan perilaku. Dengan demikian, perlu dikaji lebih lanjut mengenai hubungan antara pengetahuan terhadap perilaku penggunaan Green Packaging.

\section{METODE PENELITIAN}

Penelitian ini menggunakan pendekatan kuantitatif dengan metode survei. Objek penelitian yang diteliti adalah hubungan pengetahuan terhadap perilaku penggunaan green packaging pada masyarakat Kota Bandung, Jawa
Barat. Variabel yang diteliti adalah pengetahuan tentang bahaya sampah plastik dan green packaging, perilaku penggunaan green packaging, dan hubungan antara pengetahuan terhadap perilaku penggunaan green packaging.

Teknik pengambilan sampel yang digunakan adalah probability random sampling, yaitu teknik dengan mengambil sampel yang menawarkan peluang yang sama kepada setiap anggota populasi untuk dijadikan sampel (Sugiyono, 2015). Teknik pengambilan sampel ini dilakukan dengan mendistribusikan serangkaian kuesioner dengan acak berdasarkan kesediaan responden untuk menerima dan mengisi kuisioner secara lengkap. Alasan pemilihan teknik pengambilan sampel ini adalah untuk mempermudah pengambilan sampel. Jumlah responden yang dibutuhkan sebanyak 100 orang.

Data yang digunakan berupa data primer dan sekunder. Data primer meliputi data dari hasil wawancara dengan menggunakan kuesioner kepada responden masyarakat Kota Bandung. Data sekunder meliputi berbagai sumber pustaka, seperti buku, internet, jurnal, dan lain sebagainya sebagai pendukung penelitian. Teknik pengumpulan data 
terdiri dari observasi, wawancara dan penyebaran kuisioner serta dokumentasi.

Analisis data yang digunakan adalah tabulasi silang dan korelasi pearson. Tabulasi silang atau crosstab digunakan untuk mendeskripsikan sebaran karakteristik responden sedangkan korelasi pearson untuk menguji hubungan antara pengetahuan terhadap perilaku penggunaan green packaging.

\section{HASIL DAN PEMBAHASAN}

Karakteristik responden dijelaskan melalui karakteristik demografi yang meliputi jenis kelamin, usia, pendidikan, pekerjaan, dan pendapatan yang ditabulasikan dengan pengetahuan dan perilaku penggunaan green packaging.

Tabel 1. Karakteristik Berdasarkan Jenis Kelamin

\begin{tabular}{|c|c|c|c|c|c|c|}
\hline \multirow{2}{*}{$\begin{array}{c}\text { Jenis } \\
\text { Kelamin }\end{array}$} & \multicolumn{2}{|c|}{$\begin{array}{c}\text { Tingkat } \\
\text { Pengetahuan }\end{array}$} & \multirow[t]{2}{*}{ Total } & \multicolumn{2}{|c|}{$\begin{array}{c}\text { Perilaku } \\
\text { Penggunaan } \\
\text { Green Packaging }\end{array}$} & \multirow[t]{2}{*}{ Total } \\
\hline & $\begin{array}{c}\text { Kurang } \\
\text { Baik }\end{array}$ & Baik & & $\begin{array}{c}\text { Kurang } \\
\text { Baik }\end{array}$ & Baik & \\
\hline Laki-Laki & 9 & 35 & 44 & 25 & 19 & 44 \\
\hline Perempuan & 25 & 31 & 56 & 29 & 27 & 56 \\
\hline Total & 34 & 66 & 100 & 54 & 46 & 100 \\
\hline
\end{tabular}

Sumber : Analisis Data Primer (2020)

Dilihat dari Tabel 1 diketahui bahwa responden hampir merata antara laki-laki dan perempuan, namun untuk responden perempuan sedikit lebih banyak dibandingkan laki-laki yaitu sekitar $56 \%$ dari total keseluruhan responden yang bersedia menjawab kuesioner penelitian.
Hasil tabulasi silang jenis kelamin dengan tingkat pengetahuan dan perilaku penggunaan Green Packaging menunjukkan hasil bahwa baik laki-laki maupun perempuan di Kota Bandung sebagian besar sudah memiliki pengetahuan yang baik terhadap Green Packaging. Apabila dilihat dari perilaku penggunaan Green Packaging, baik lakilaki dan perempuan, cenderung memiliki perilaku kurang baik meskipun jumlahnya tidak jauh dengan yang baik.

Tabel 2. Karakteristik Berdasarkan Usia

\begin{tabular}{|c|c|c|c|c|c|c|}
\hline \multirow{2}{*}{$\begin{array}{l}\text { Usia } \\
\text { (tahun) }\end{array}$} & \multicolumn{2}{|c|}{$\begin{array}{c}\text { Tingkat } \\
\text { Pengetahuan }\end{array}$} & \multirow{2}{*}{ Total } & \multicolumn{2}{|c|}{$\begin{array}{c}\text { Perilaku } \\
\text { Penggunaan } \\
\text { Green Packaging }\end{array}$} & \multirow{2}{*}{ Total } \\
\hline & $\begin{array}{c}\text { Kurang } \\
\text { Baik }\end{array}$ & Baik & & $\begin{array}{c}\text { Kurang } \\
\text { Baik }\end{array}$ & Baik & \\
\hline$<18$ & 2 & 0 & 2 & 0 & 2 & 2 \\
\hline $18-28$ & 29 & 17 & 46 & 23 & 23 & 46 \\
\hline 29-39 & 1 & 19 & 20 & 11 & 9 & 20 \\
\hline$>40$ & 2 & 30 & 32 & 20 & 12 & 32 \\
\hline Total & 34 & 66 & 100 & 54 & 46 & 100 \\
\hline
\end{tabular}

Sumber : Analisis Data Primer (2020)

Tabel 2 menunjukkan bahwa usia responden dalam penelitian didominasi oleh masyarakat yang berusia kisaran 1828 tahun dengan presentase hampir setengah dari keseluruhan jumlah responden (46\%). Hasil tabulasi silang usia dengan tingkat pengetahuan dan perilaku penggunaan Green Packaging menunjukkan hasil bahwa masyarakat di Kota Bandung sebagian besar sudah memiliki pengetahuan yang baik terhadap Green Packaging.

Namun, apabila dilihat dari perilaku penggunaan Green Packaging, 
masyarakat dengan usia $<18$ tahun dan rentang usia 18-28 tahun sudah berusaha untuk berperilaku baik menggunakan Green Packaging, sedangkan sisanya hampir merata namun cenderung kurang baik. Hal tersebut dapat disimpulkan bahwa meski belum memiliki pengetahuan yang baik tentang Green Packaging bukan berarti berperilaku buruk atau tidak mau menggunakan Green Packaging dalam kehidupan sehari-hari.

Tabel 3. Karakteristik Berdasarkan Tingkat Pendidikan

\begin{tabular}{|c|c|c|c|c|c|c|}
\hline \multirow[t]{2}{*}{ Pendidikan } & \multicolumn{2}{|c|}{$\begin{array}{c}\text { Tingkat } \\
\text { Pengetahuan }\end{array}$} & \multirow[t]{2}{*}{ Total } & \multicolumn{2}{|c|}{$\begin{array}{c}\text { Perilaku } \\
\text { Penggunaan } \\
\text { Green } \\
\text { Packaging }\end{array}$} & \multirow[t]{2}{*}{ Total } \\
\hline & $\begin{array}{c}\text { Kurang } \\
\text { Baik }\end{array}$ & Baik & & $\begin{array}{c}\text { Kurang } \\
\text { Baik }\end{array}$ & Baik & \\
\hline SD & 2 & 7 & 9 & 4 & 5 & 9 \\
\hline SMP & 4 & 9 & 13 & 7 & 6 & 13 \\
\hline SMA & 25 & 21 & 46 & 24 & 22 & 46 \\
\hline $\mathrm{D} 3 / \mathrm{S} 1 / \mathrm{S} 2$ & 3 & 29 & 32 & 19 & 13 & 32 \\
\hline Total & 34 & 83 & 100 & 54 & 46 & 100 \\
\hline
\end{tabular}

Sumber : Analisis Data Primer (2020)

Berdasarkan Tabel 3 dapat diketahui bahwa untuk tingkat pendidikan dari 100 responden hampir setengahnya berpendidikan akhir SMA sebanyak 46\%. Hasil tabulasi silang tingkat pendidikan dengan tingkat pengetahuan dan perilaku penggunaan Green Packaging menunjukkan hasil bahwa sebagian besar responden dari beragam latar pendidikan sudah memiliki pengetahuan yang baik terhadap Green Packaging.
Apabila dilihat dari perilakunya, masih banyak yang berperilaku kurang baik atau belum menggunakan Green Packaging dalam kehidupan sehari-hari, meski pun jumlahnya tidak jauh beda dengan yang sudah berperilaku baik atau menggunakan Green Packaging.

Tabel 4. Karakteristik Berdasarkan Pekerjaan

\begin{tabular}{|c|c|c|c|c|c|c|}
\hline \multirow{2}{*}{ Pekerjaan } & \multicolumn{2}{|c|}{$\begin{array}{c}\text { Tingkat } \\
\text { Pengetahuan }\end{array}$} & \multirow{2}{*}{ Total } & \multicolumn{2}{|c|}{$\begin{array}{c}\text { Perilaku Penggunaan } \\
\text { Green Packaging }\end{array}$} & \multirow{2}{*}{ Total } \\
\hline & $\begin{array}{l}\text { Kurang } \\
\text { Baik }\end{array}$ & Baik & & $\begin{array}{c}\text { Kurang } \\
\text { Baik }\end{array}$ & Baik & \\
\hline Pelajar/Mahasiswa & 27 & 0 & 27 & 10 & 17 & 27 \\
\hline PNS & 0 & 8 & 8 & 5 & 3 & 8 \\
\hline Pegawai Swasta & 0 & 13 & 13 & 9 & 4 & 13 \\
\hline Wiraswasta & 4 & 8 & 12 & 6 & 6 & 12 \\
\hline Lainnya & 3 & 37 & 40 & 24 & 16 & 40 \\
\hline Total & 34 & 66 & 100 & 54 & 47 & 100 \\
\hline
\end{tabular}

Sumber : Analisis Data Primer (2020)

Dari Tabel 4 dapat dilihat bahwa jenis pekerjaan masyarakat di Kota Bandung dari 100 responden beragam, namun paling banyak berstatus sebagai ibu rumah tangga atau pensiunan sebanyak $40 \%$. Hasil tabulasi silang pekerjaan dengan tingkat pengetahuan dan perilaku penggunaan Green Packaging menunjukkan hasil bahwa masyarakat di Kota Bandung sebagian besar sudah memiliki pengetahuan yang baik terhadap Green Packaging, hanya masyarakat yang berstatus sebagai pelajar/mahasiswa yang masih memiliki pengetahuan yang kurang tentang Green Packaging.

Dilihat dari perilaku penggunaan Green Packaging, hanya masyarakat yang berprofesi sebagai pelajar/ 
mahasiswa dan wiraswasta yang menunjukkan hasil sudah banyak yang berperilaku baik sedangkan sisanya mayoritas masih kurang baik.

\begin{tabular}{|c|c|c|c|c|c|c|}
\hline \multirow{3}{*}{ Pendapatan } & \multicolumn{3}{|c|}{$\begin{array}{l}\text { Karakteristik } \\
\text { Pendapatan }\end{array}$} & \multicolumn{3}{|c|}{ Berdasarkan } \\
\hline & \multicolumn{2}{|c|}{$\begin{array}{c}\text { Tingkat } \\
\text { Pengetahuan }\end{array}$} & \multirow[t]{2}{*}{ Total } & \multicolumn{2}{|c|}{$\begin{array}{c}\text { Perilaku } \\
\text { Penggunaan } \\
\text { Green } \\
\text { Packaging }\end{array}$} & \multirow[t]{2}{*}{ Total } \\
\hline & $\begin{array}{c}\text { Kurang } \\
\text { Baik }\end{array}$ & Baik & & $\begin{array}{l}\text { Kurang } \\
\text { Baik }\end{array}$ & Baik & \\
\hline$<1$ juta & 24 & 20 & 44 & 22 & 22 & 44 \\
\hline $1-3$ juta & 8 & 21 & 29 & 15 & 14 & 29 \\
\hline$>3$ juta & 2 & 25 & 27 & 17 & 10 & 27 \\
\hline Total & 34 & 66 & 100 & 54 & 46 & 100 \\
\hline
\end{tabular}

Sumber : Analisis Data Primer (2020)

Tabel 5 menjelaskan masyarakat Kota Bandung dari 100 responden cenderung beragam, dari mulai di bawah Rp 1.000.000 hingga lebih dari Rp 3.000.000. Namun demikian, dari 100 responden masyarakat Kota Bandung, terbanyak memiliki pendapatan di bawah Rp 1.000.000 yaitu sebanyak 44\%.

Hasil tabulasi silang pendapatan dengan tingkat pengetahuan dan perilaku penggunaan Green Packaging menunjukkan hasil bahwa masyarakat di Kota Bandung sebagian besar sudah memiliki pengetahuan yang baik terhadap Green Packaging. Hanya masyarakat yang memiliki pendapatan $<1$ juta yang masih dominan kurang memiliki pengetahuan tentang Green Packaging, sedangkan sisanya mayoritas sudah memiliki pengetahuan yang baik tentang Green Packaging.
Sedangkan apabila dilihat dari perilaku penggunaan Green Packaging, masyarakat sudah mulai menunjukkan perilaku yang baik atau sudah menggunakan Green Packaging dalam kehidupan sehari-hari meskipun masih sedikit lebih banyak yang belum menggunakan Green Packaging.

Tabel 6. Hasil Uji Korelasi Pearson

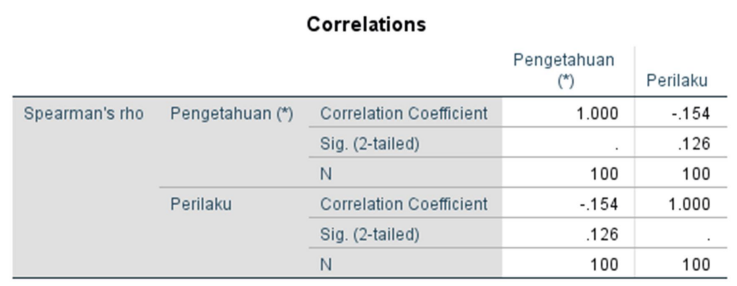

Sumber : Analisis Data Primer (2020)

Dengan taraf signifikansi $5 \%$ diperoleh bahwa nilai korelasi pearson (rhitung) untuk hubungan pengetahuan dengan perilaku penggunaan Green Packaging adalah sebesar -0.154 dimana jika dibandingkan dengan nilai r-tabel yang bernilai sebesar 0.1966, nilai $r-$ hitung $<$ r-tabel, serta nilai signifikansi antara pengetahuan dengan perilaku adalah sebesar 0.126 dimana nilai tersebut lebih besar daripada taraf signifikansi sebesar $5 \%$ sehingga $\mathrm{H}_{0}$ diterima, yang berarti semakin tinggi pengetahuan tidak berpengaruh baik terhadap perilaku penggunaan Green Packaging pada masyarakat Kota Bandung, Jawa Barat. 
Nilai korelasi spearman (r-hitung) dalam analisis ini memiliki hubungan yang sangat lemah dan bernilai negatif yang berarti semakin meningkatnya pengetahuan maka tidak membuat perilaku baik dalam menggunakan Green Packaging. Tabel 6 menunjukkan bahwa tingkat pengetahuan yang kurang baik terhadap Green Packaging ternyata dapat juga menimbulkan perilaku baik menggunakan Green Packaging meski jumlahnya tidak banyak, dan pengetahuan yang baik belum tentu menimbulkan perilaku baik dalam penggunaan Green Packaging yang lebih tinggi daripada berperilaku tidak baik.

Penelitian terkait hubungan pengetahuan terhadap perilaku penggunaan Green Packaging belum banyak dilakukan khususnya di Indonesia, namun sudah banyak penelitian sejenis yang mencari hubungan antara pengetahuan dengan perilaku. Salah satunya adalah penelitian yang dilakukan oleh Mailinda dan Lestari (2019) terkait tentang hubungan pengetahuan terhadap perilaku pemilihan snack sehat pada siswa kelas 4 dan 5 Sekolah Dasar, di mana hasilnya menunjukkan bahwa pengetahuan yang baik tidak selalu menjamin seseorang berperilaku baik.
Penelitian lain yang mendukung hasil penelitian juga dilakukan oleh Mnguni et al (2015) yang menunjukkan hasil bahwa pengetahuan tidak berhubungan dengan perilaku seseorang terkait HIV/AIDS. Selanjutnya Fah \& Sirisena (2014) juga menyatakan dalam penelitiannya bahwa pengetahuan tentang lingkungan tidak berpengaruh signifikan terhadap perilaku siswa. Hasil penelitian ini tentu berbeda dengan hasil yang didapat oleh Fauzia et al (2016) dan Sudiharti dan Solikhah (2012) yang menyebutkan bahwa terdapat hubungan antara positif antara pengetahuan terhadap perilaku tertentu.

Tidak ada hubungan antara pengetahuan terhadap perilaku penggunaan Green Packaging pada masyarakat Kota Bandung dapat disebabkan oleh beberapa hal, di antaranya masyarakat masih memilih halhal yang praktis dan tidak ribet. Semakin canggihnya teknologi yang ada saat ini membuat semuanya jadi serba menjadi mudah, salah satunya adalah delivery order untuk makanan. Saat sedang sibuk dan tidak memiliki banyak waktu, masyarakat banyak yang memilih memesan makanan secara online yang akhirnya berdampak pada penambahan volume sampah plastik. 
Berdasarkan hasil penelitian masyarakat juga masih banyak masyarakat yang lebih memilih membayar kantong plastik Rp 200 saat berbelanja daripada harus membawa kantong belanja sendiri. Maka dari itu perilaku-perilaku seperti itu harus mulai dikurangi perlahan-lahan dengan menggunakan green packaging, karena hal ini merupakan salah satu cara menurunkan jumlah penggunaan kantong plastik. Hal tersebut sejalan dengan penelitian yang dilakukan oleh Deliana et al (2017) yang menyatakan bahwa green packaging itu perlu diterapkan untuk mengurangi jumlah volume sampah kantong plastik.

Faktor yang paling mempengaruhi penggunaan Green Packaging pada masyarakat Kota Bandung yaitu faktor media sosial dan lingkungan sosial sekitar. Hal tersebut sesuai dengan hasil lapangan yang menunjukkan bahwa masyarakat ingin berusaha beralih ke Green Packaging bukan sekedar karena rasa peduli lingkungan, melainkan faktor lain yang mempengaruhi seperti banyaknya influencer atau idola mereka yang melakukan edukasi dan mengadakan campaign mendukung Green Packaging di media social, dan juga lingkungan sosial sekitarnya yang mendukung masyarakat untuk melakukan kegiatan yang sama terutama dalam jejaring sosial kaum muda yang memiliki kecenderungan untuk mempengaruhi perspektif dan memperkuat perilaku (Deliana dan Rum, 2019).

\section{KESIMPULAN DAN SARAN}

Semakin tinggi tingkat pengetahuan tidak menjamin akan berpengaruh baik terhadap perilaku penggunaan Green Packaging pada masyarakat Kota Bandung. Hal tersebut dapat disebabkan oleh beberapa hal, di antaranya masyarakat meski memiliki pengetahuan baik tentang bahaya plastik namun masih memilih hal-hal yang praktis dan tidak ribet, salah satunya adalah delivery order untuk makanan yang akhirnya berdampak pada penambahan volume sampah plastik. Selain itu, masih banyak masyarakat yang lebih memilih membayar kantong plastik Rp 200 saat berbelanja daripada harus membawa kantong belanja sendiri.

Pemerintah, khususnya pemerintah daerah, membuat peraturan yang lebih jelas dengan sanksi yang tegas untuk masyarakat dalam upaya pengurangan penggunaan plastik. Selain itu, pemerintah juga perlu memfasilitasi kelompok-kelompok sadar lingkungan 
untuk dapat terus mengedukasi dan melatih masyarakat untuk beralih ke Green Packaging. Di lain sisi, kantorkantor, sekolah, lingkungan tempat tinggal perlu diedukasi dan melakukan kewajiban pengurangan penggunaan plastik dengan setidaknya mewajibkan menggunakan botol minum dan tempat makan sendiri.

\section{DAFTAR PUSTAKA}

Carlson, K. (2009). Green your work. Adam Business: Avon, MA, USA.

Choudhary, Aparna \& Samir Gokarn. (2013). Green marketing: A means for sustainable development. Journal of Arts, Science \& Commerce, Volume IV Issue 3(3), 26-32

Deliana, Y., Djuendah, E., Kusnadi, E., \& Sendjaja, T. P. (2017). The perception of green marketing (A Case in Jatinangor, West Java Province, Indonesia). International Journal of Economics Research, 14, 201-215

Deliana, Y., \& Rum, I. A. (2019). How does perception on green environment across generations affect consumer behaviour? A neural network process. International Journal of Consumer Studies, 43(4), 358-367.

Fah, Lay Yoon., \& Sirisena, Anuthra. (2014). Relationship Between The Knowledge, Attitudes, and Behaviour Dimensions of Enviromental Literacy: A Structural Equation Modeling Approach Using Smartpls. Journal for Educational Thinkers, 5,119-114.

Fauzia, RA., Rahmi, Fl., Nugroho, Trilaksana. (2016). Hubungan
Tingkat Pengetahuan Dengan Perilaku Memeriksa Diri Ke Pelayanan Kesehatan: Penelitian Pada Pasien Glaukoma Di Rumah Sakit Dr. Kariadi. Jurnal Kedokteran Diponegoro, 5(4).

Jambeck, J. R., Geyer, R., Wilcox, C., Siegler, T. R., Perryman, M., Andrady, A., ... \& Law, K. L. (2015). Plastic waste inputs from land into the ocean. Science, 347(6223), 768771.

Mailinda, E., \& Lestari, R. F. (2019). The relationship between level of knowledge and attitude towards behavior in choosing healthy snacks of 4th and 5th grade students. Enfermeria clinica, 29, 81-84.

Mnguni, L., Abrie, M., \& Ebersohn, L. (2015). The Relationship Between Scientific Knowledge and Behaviour: An HIV/AIDS Case. Journal of Biological Education, 50(2), 147159.

Qodriyatun, Sri N. (2018). Sampah Plastik: Dampaknya Terhadap Pariwisata dan Solusi. Kajian Singkat Terhadap Isu Aktual dan Strategis

Rosadi, Farida. (2019). "Darurat Sampah Bukan Fatamorgana". Dalam Bumi Kantong Plastik Majalah Media Keuangan, September,XIV.Jakarta: Sekretariat Jenderal Kementrian Keuangan

Setiyaningrum Ari, Jusuf Udaya, Efendi. (2015). Prinsip-Prinsip Pemasaran. Yogyakarta: Andy.

Sudiharti, S., \& Solikhah, S. (2012). Hubungan pengetahuan dan sikap dengan perilaku perawat dalam pembuangan sampah medis di rumah sakit PKU Muhammadiyah Yogyakarta. Kes Mas: Jurnal Fakultas Kesehatan Masyarakat Universitas Ahmad Daulan, 6(1), 24951. 
Sugiyono. (2015). Metode Penelitian Pendidikan Pendekatan Kuantitatif, Kualitatif dan R\&D. Bandung: Alfabeta.
Sukriah, Erry. (2014). Pariwisata Sebagai Sektor Unggulan Kota Bandung. Jurnal Manajemen Resort \& Leisure, 11(1). 